\title{
VALUE ADDITION AND PROCESSED PRODUCTS OF THREE INDIGENOUS FRUITS IN NAMIBIA
}

\section{Bille $\mathrm{PG}^{1}$, Shikongo- Nambabi $\mathrm{M}^{1}$ and A Cheikhyoussef ${ }^{2 *}$}

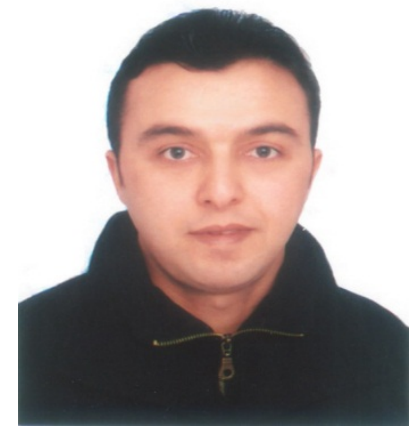

Ahmad Cheikhyoussef

Corresponding author email: acheikyoussef@gmail.com

${ }^{1}$ Department of Food Science and Technology, Faculty of Agriculture and Natural Resources, University of Namibia, Private Bag 13301, Windhoek, Namibia.

${ }^{2}$ Indigenous Knowledge System Technology (IKST) Food program, Science, Technology and Innovation Division, Multidisciplinary Research Centre (MRC),University of Namibia, Private Bag 13301, Windhoek, Namibia. 


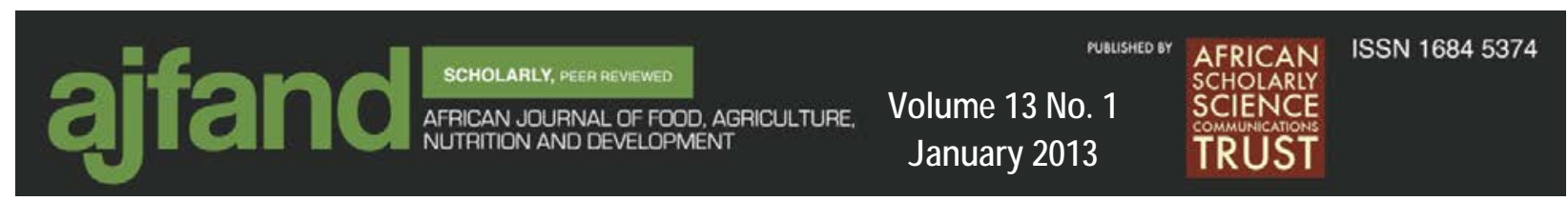

\section{ABSTRACT}

The objectives of this study were to add value to three popular indigenous fruits found in Namibia namely, Marula (Sclerocarya birrea), Monkey orange (Strychnos cocculoides) and Eembe (Berchemia discolour) into processed food products and to train rural communities on value addition for job creation, income generation and food security. Indigenous fruits are receiving increasing interests from researchers and scholars because of their nutrition and abundance in most African countries. The fruits are important sources of food for rural communities especially at times of food shortage, hunger and other disasters. In addition, they provide enormous health benefits such as antioxidants, vitamins and minerals. They are also known to create jobs and generate income for rural communities. Because of their role in combating food insecurity, nutrition and the problems of seasonality, studies on their value addition were carried out in Namibia. Different types of food products were made from the fruits namely; juice, jam, jelly and muffins (cakes). A pilot study was carried out to determine the levels and preference range of ingredients in the mix to formulate recipes of the products prior to processing and training the community members. The results were subjected to paired preference tests and the best ratio was then used. According to consumer preference test, marula juice was on the lower value (2.3) due to its low $\mathrm{pH}$ (3.26). As for jam and jelly; quality, taste and colour were acceptable and preferred. The three products made from monkey orange were all preferred but those from eembe were downgraded (2.31-3.20) due to dark colour and lack of flavour. The microbiological quality of the produced products confirmed their safety characteristics. The products made in this study were shown to be viable, of good quality and good sources of income for rural communities. The fruit flavour from marula and monkey orange can be utilized in the dairy and other soft drink industries for making yoghurts, sour milk, ice cream, juices and jams.

Key words: Indigenous fruits, Value addition, Namibia 


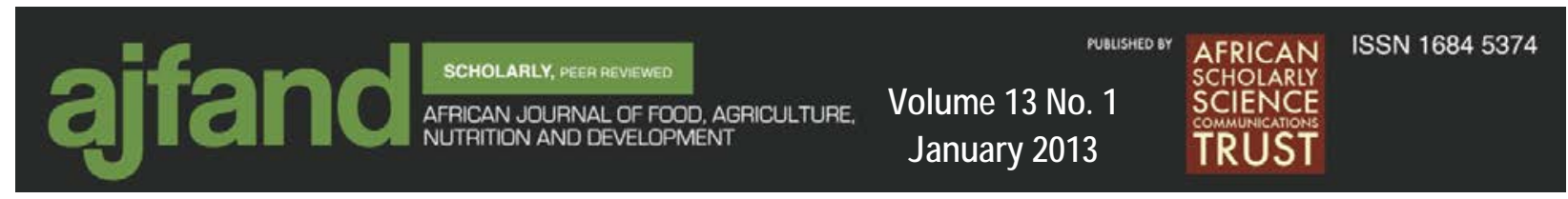

\section{INTRODUCTION}

In developing countries like Namibia, data on product development from indigenous fruits is very scarce and if available, are related only to exotic fruits. Natural resources are of great importance to rural communities since they provide many useful materials for their daily life. One of these important resources is the indigenous fruit trees which provide food in the form of fruit, nuts, and wood for fuel and building material. They also serve as a source of job creation and income generation for the rural communities at large. Consumption of wild fruits that contain antioxidants (phenolic compounds, ascorbate and carotenoids) has been associated with lowered incidences of degenerative diseases including cancer, heart disease, inflammation, arthritis, immune system decline, brain dysfunction and cataracts [1]. Indeed, among the functional compounds in fruits which have been widely studied, apart from vitamins and minerals, is the family of antioxidants [2]. The importance of wild fruits in the diet depends to a large extent on their availability for domestic use.

Most fruits are seasonal and are consumed in spring and summer and their consumption has been associated with potential health benefits [3]. The wild fruits are important sources of food for rural communities especially at times of food shortage, hunger and other disasters. In addition, they provide enormous health benefits such as antioxidants, vitamins and minerals. They are also known to create jobs and generate income for rural communities. The World Health Organization (WHO) and Food and Agricultural Organization (FAO) recommended the daily consumption of at least 400 $\mathrm{g}$ of fruits and vegetables for the prevention of heart diseases, cancer, type-2 diabetes and obesity [4]. Unfortunately, indigenous fruit trees have been given very little attention, both in research and extension, though they are important in the diet [5]. The indigenous fruit trees play a very important role in rural communities in Namibia [6] and Botswana [7]. However, there many threats affecting the wild fruit trees, just like in cultivated fields. Fruit trees are cut down in areas where wood is scarce and are used for fuel and building material. The trees are also often cut down from cultivated fields particularly where tractors are used for ploughing. With this background, research and extension on wild fruit trees should be given priority, otherwise with time this valuable resource may disappear [8].

Marula (Sclerocarya birrea), Monkey orange ( Strychnos cocculoides) and Eembe (Berchemia discolour) are traditionally important indigenous fruit trees in Namibia, which in recent years have also become commercially important as the fruits and their products have entered local, regional and international markets especially for marula products $[9,10,11,12,13]$. Nutritionally, marula is an important source of several micro-nutrients, with high content of vitamin C $[14,15]$. The flesh commonly contains 180 mg vitamin C per 100 g, but can go even higher. In this regard, marula outshines orange, grapefruit and lemon. Marula is also a rich food energy source; the kernel normally contains around 700 calories per $100 \mathrm{~g}$ and surpasses the nutritive value of globally famous nuts such as almonds, chestnuts and hazelnuts [16,17]. Because of their fine taste, marula nuts are regarded a delicacy, but their fat, protein and mineral contents make them a crucial food supplement during the drought or food scarcity $[15,16]$. Eembe can be fermented to make strong local liquor like spirit or wine 


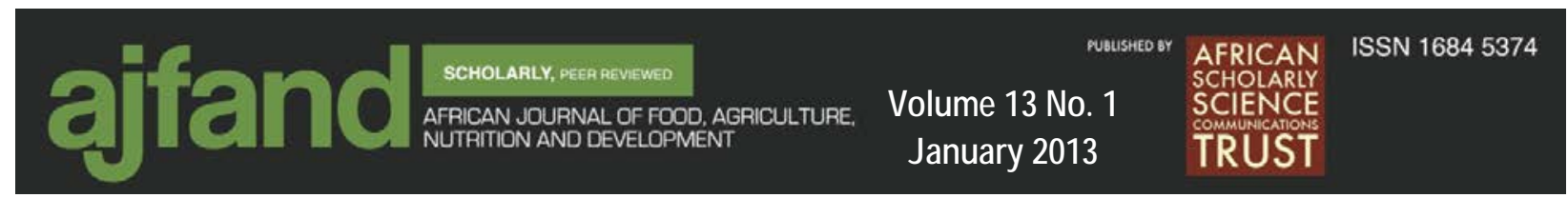

$[18,19]$. Nutritionally, the sugar content of eembe pulp is high (30\%) and contains minerals (K, Ca, Mg, P) and Vitamin C (65 mg/100g) [17]. The fruit is a rich source of many phytochemical compounds such as terpenoids, total phenols, saponins, flavonoid, tannins and cardiac glycoside [10]. Not much is known about nutritional value of monkey orange, but it was reported that it is rich in B vitamins and vitamin $C$ [17].

The consumption of fruits with high contents of antioxidant(s) has been associated with a lowered incidence of degenerative diseases including cancer, heart disease, inflammation, arthritis, immune system, brain dysfunctions, and cataracts [4]. Most of these antioxidants are polyphenols, which show biological activity as antibacterial, anti-carcinogenic, anti-inflammatory, antiviral and immune-stimulating effects [16]. Compared to exotic fruit species, very little research work has been done on value addition of indigenous fruits in Namibia. Most of the indigenous fruits are edible and they can play an important role in the diets of rural communities but information on sustainability, transformation and value addition of these fruits is scarce [20]. Therefore, the aim of this study was therefore, to add value to three indigenous fruits (Marula, Monkey orange and Eembe) by processing into different food products on the basis of community needs and to train rural communities on value addition in Namibia. The training knowledge and skills provided will help communities to improve their livelihood by contributing to job creation, income generation and household food security.

\section{MATERIALS AND METHODS}

\section{Raw Materials}

Marula (Sclerocarya birrea) and Monkey Orange (Strychnos cocculoides) were collected from individual households in Oshana and Ohangwena regions of Namibia respectively. Eembe (Berchemia discolour) were purchased from Oshakati local market. The fruits were collected in clean plastic bags and packed in cool boxes with ice. All samples were sent to the Department of Food Science and Technology at Neudamm Campus of the University of Namibia for processing and value addition. Granulated sugar, food colours, essences and pectin were procured from the supermarkets in Windhoek, Namibia.

\section{Preparations of the fruits}

The fruits were sorted out for ripeness, cracks and freshness and they were washed to remove sand and soils in order to avoid contamination of pulps and juice with soils and microorganisms. Marula fruits were then pressed to extract juice and pulp using a juice presser. Monkey Orange was first crushed to remove the outer hard cover and seeds and then processed as above. Eembe fruits were brought in dry-form. They had to be soaked in clean portable water overnight in order to soften them and separate the extract from the seeds, peel and from the pulp. Finally the pulps and juices from all the fruits were filtered or clarified to separate the extract from seeds, fibers and other foreign materials before use $[9,11,12,13]$. 


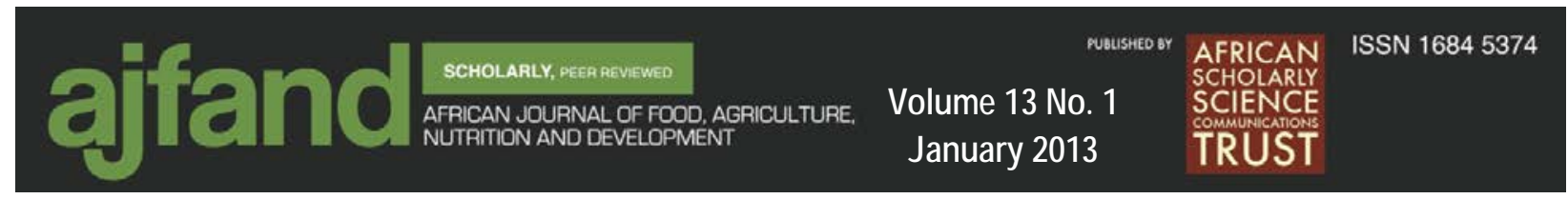

\section{Improved processing method of the fruits}

The method described by Omobuwajo [13] was modified to determine the quantities of various ingredients to be used in the formulation of recipes to add value to products made from marula, monkey orange and eembe fruits. A pilot study was carried out on each fruit type product to determine the acceptable average range of pulp to water blend with sugar, colour and flavour. After several trials treatments, the results were subjected to paired preference test $[21,22]$ and the best ratio described on each fruit product was then used and mixed with various quantities of other ingredients to make recipes.

\section{Marula juice}

The marula juice process is shown in the following flow chart (Figure 1).

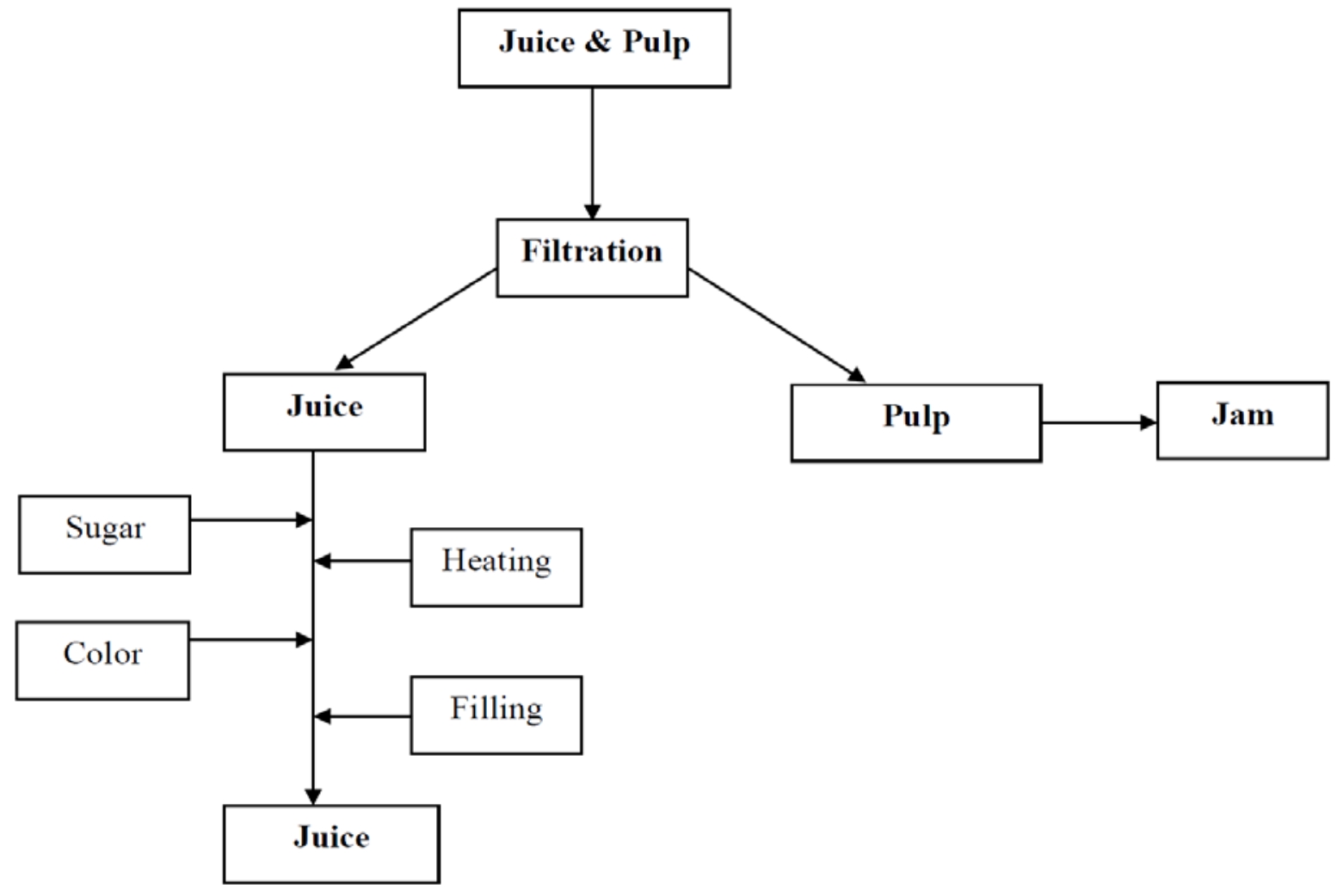

\section{Figure 1: Flow chart for processing juice from marula}

Marula juice had a very sour taste with a low $\mathrm{pH}$ of 3.26. The juice was sieved to remove larger particles or pulp which was saved and used in jam making. The clear sour juice 1.5 Lt was neutralized with food grade N/10 Sodium hydroxide solution to reduce acidity to a $\mathrm{pH}$ of 4.0. Also $300 \mathrm{~g}$ sugar and one drop of commercial food colour (egg yellow) were added according to recipe in order to improve the taste, product colour and to reduce the sourness of the juice $[9,11,12,13]$. Juice was pasteurized to $80^{\circ} \mathrm{C}$ for $30 \mathrm{~min}$ in order to destroy microorganism and inactivate spoilage enzymes. The juice was then filled hot into sterile bottles, sealed and tilted to 


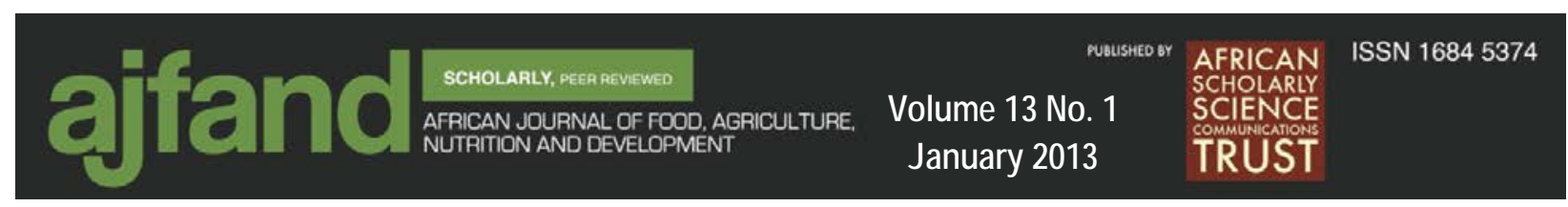

sterilize head space and refrigerated to cool. Samples for analysis were taken at this stage.

\section{Marula jam}

An amount; 50g of marula pulp and $1.5 \mathrm{Lt}$ of marula juice were mixed and blended together before boiling to cook the pulp. $0.2 \%$ of pectin and $1 \mathrm{~kg}$ of sugar was used in the recipe. After the first heating process, pectin mixed with a little sugar was added into the blend and mixed in order to prevent lumping. The mixture was again brought to a boil and kept boiling for one minute. The rest of the sugar was added at this stage and mixed. Jam was then filled hot into sterile jars, leaving a headspace, sealed, tilted to sterilize head space and left to cool over night to jell at ambient temperature. Samples were taken at this stage for analysis (Fig.2).

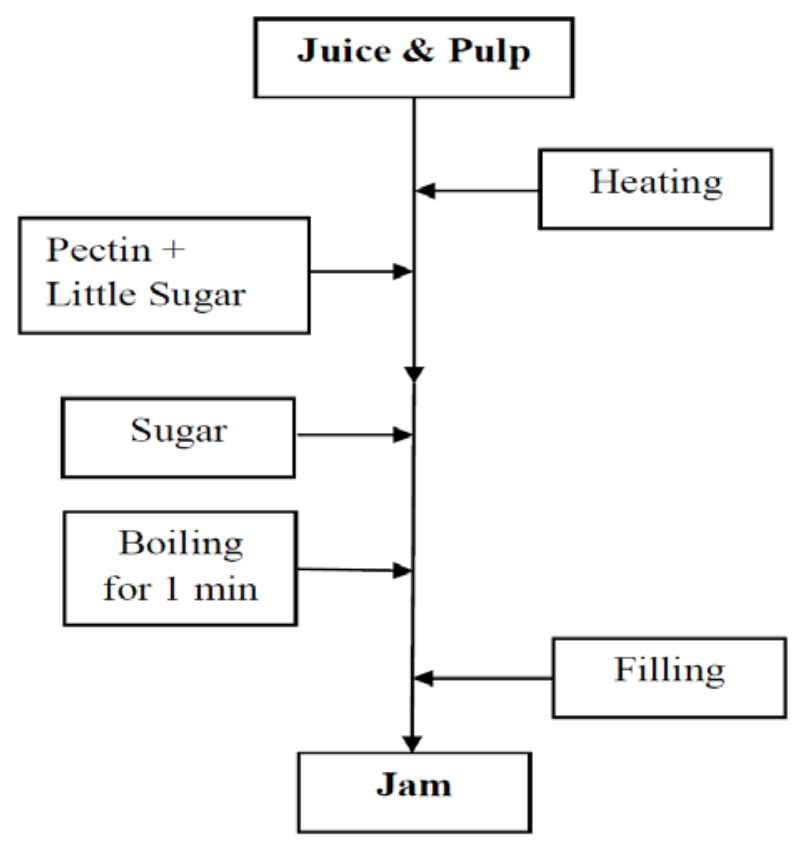

Figure 2: Flow chart for processing jam from marula

\section{Marula jelly}

Similarly, marula jelly was prepared from clarified $2 \mathrm{Lt}$ Juice in the same way the jam was made with $1 \mathrm{~kg}$ sugar and $0.2 \%$ pectin, but without the pulp (Fig 3). 


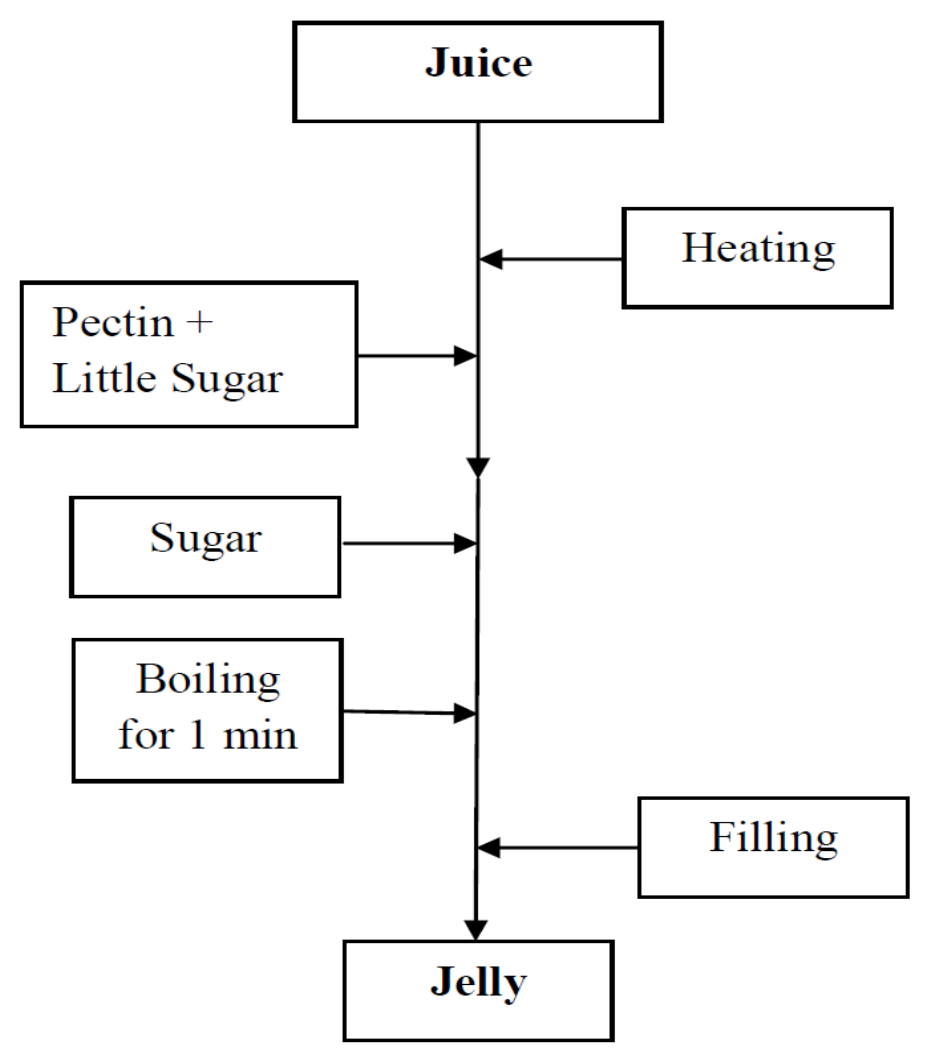

Figure 3: Flow chart for processing jelly from marula

The jelly was then filled hot into sterilized jars, sealed, tilted and stored at room temperature to jell and was ready for use. Samples were taken at this stage for analysis.

\section{Monkey Orange juice}

The monkey orange juice was prepared by extracting pulp and juice from the fruits. In the first stage, shells of the fruit were cracked and separated from the pulp. The shells were discarded. The pulp was mashed manually in a big container. The seeds were removed before kneading the pulp with a small amount of portable water using a food processor for ten minutes and sieved to obtain juice. This process was repeated until all the juice was extracted from the pulp. The removed pulp was saved for jam making. One litre of juice was then pasteurized to $80^{\circ} \mathrm{C} / 30$ min to destroy enzymes and to kill microorganisms. An amount of 200 g sugar and 1 tea soon of egg yellow food colour were added according to the recipe in order to improve taste and appearance respectively (Fig.4). The juice was then filled hot in sterile bottles, sealed and cooled before sampling for analysis and consumption. 

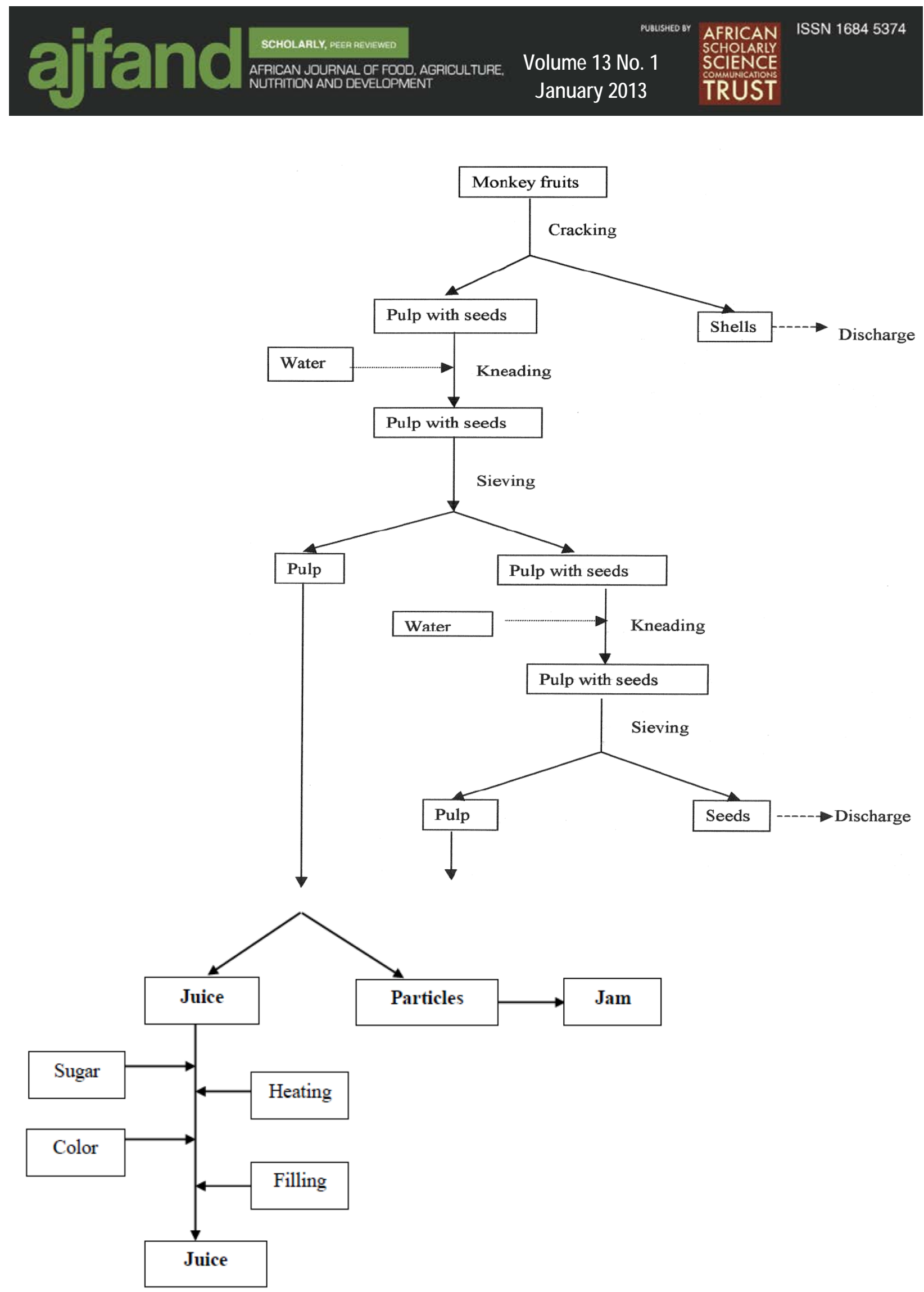

Figure 4: Flow chart for processing juice from monkey orange 


\section{Monkey Orange Jam}

An amount of $1.3 \mathrm{~kg}$ of pulp and juice blend from monkey orange fruit was boiled to cook the pulp. After that; $0.2 \%$ pectin mixed with a small amount sugar from $650 \mathrm{~g}$ to avoid lumping were mixed and dissolved into the pulp mixture. The rest of the sugar was added together with 1 table spoon of food colour (Fig. 5). The mixture was then heated to boiling point for 1 minute as indicated previously and filled hot, sealed, tilted to sterilize head space and stored overnight at room temperature to jell before sampling for analysis and consumption.

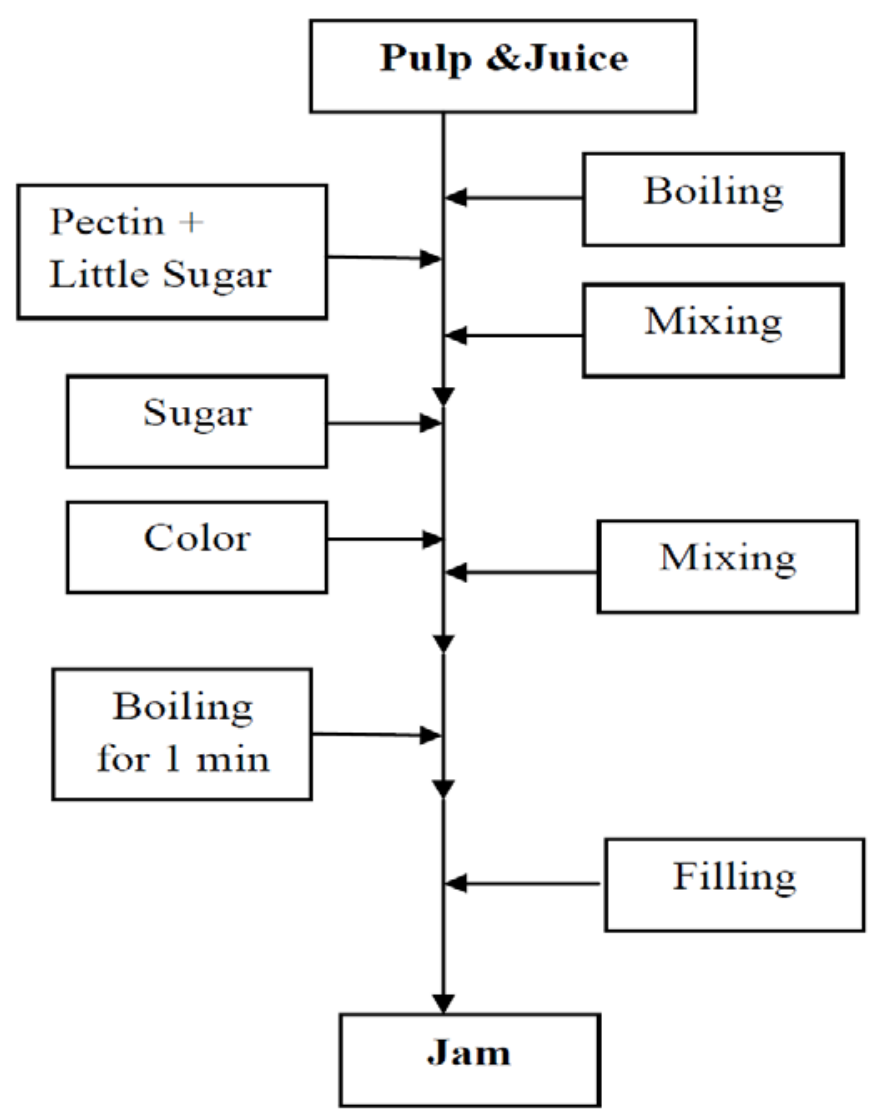

Figure 5: Flow chart for processing jam from monkey orange

\section{Making of Muffins from monkey orange}

The making of monkey orange muffins/cake is shown in the following flow chart (Fig 6). 

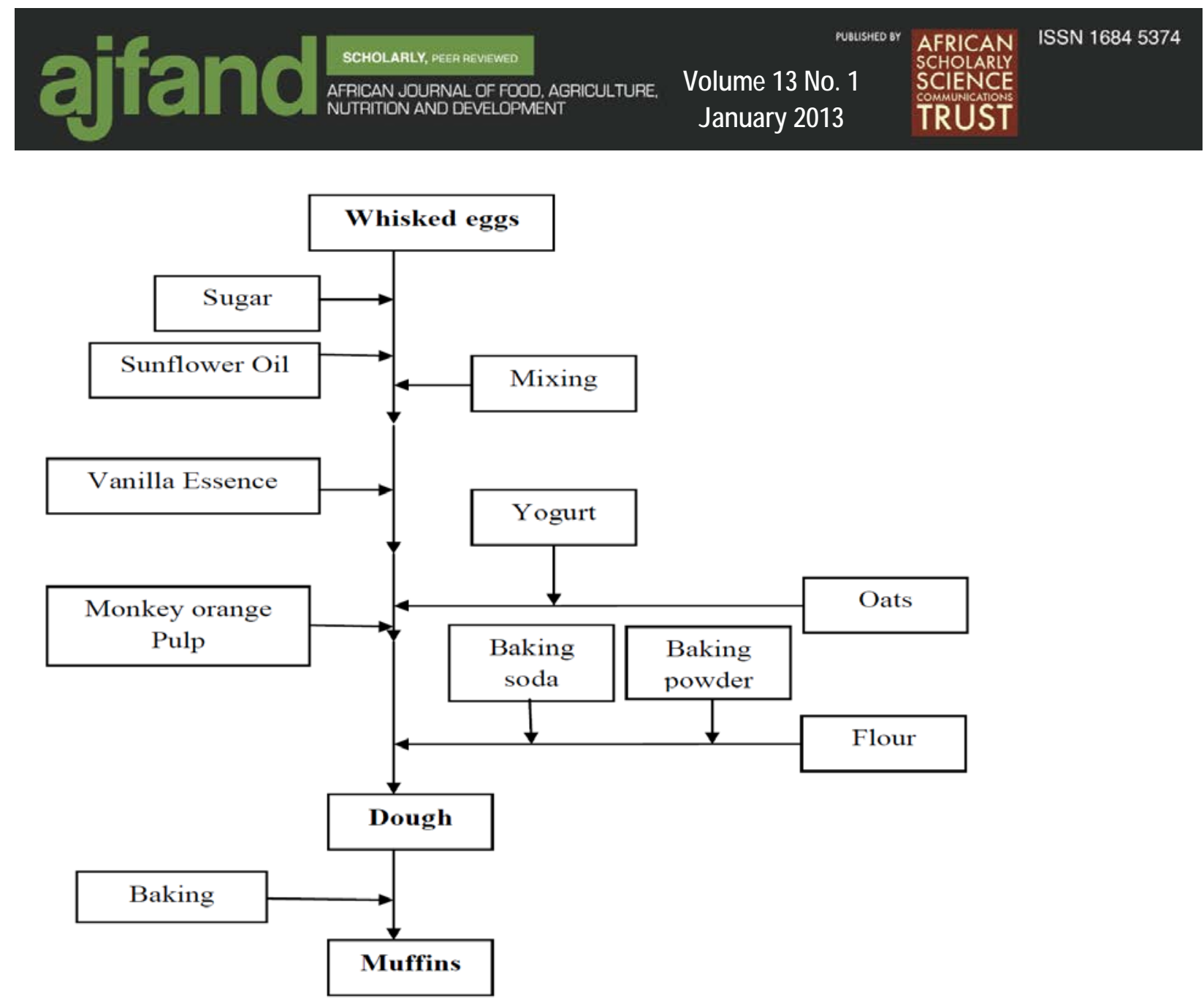

Figure 6: Flow chart for processing muffins from monkey orange

An amount of $90 \mathrm{~g}$ of Oats were soaked in $150 \mathrm{ml}$ of yoghurt for 10 minutes. While soaking, dry ingredients like $250 \mathrm{~g}$ of cake flour, 1 teaspoon of baking powder and $1 / 2$ teaspoon of baking soda were mixed. An egg was whisked until the colour changed to white. $140 \mathrm{~g}$ sugar, $80 \mathrm{ml}$ sunflower oil, 1 teaspoon of vanilla essence and $1 \mathrm{~kg}$ of fresh monkey orange pulp were mixed. The oat-yoghurt mixture was then incorporated into all the ingredients and dough was made and transferred into the greased molds and baked at $180^{\circ} \mathrm{C}$ for 30 minutes or to a golden brown colour. Muffins were allowed to cool and were ready for sensory evaluation.

\section{Processing of juice from Eembe}

Eembe fruits were collected in dry-form and they had to be soaked overnight in potable water to soften. This was done after sorting, washing and cleaning in order to extract juice and pulp from the peel or skin and seeds. The pulp was rather viscous, so portable water was added, kneaded to release seeds and fiber and then filtered to obtain juice (Fig.7). The pulp was then saved for jam and for muffins. $1 \mathrm{Lt}$ of juice was then pasteurized to $80^{\circ} \mathrm{C} / 30$ min to kill microbes and destroy enzymes. An amount of $150 \mathrm{~g}$ of sugar, 2 teaspoons of food egg yellow colour and 2 teaspoons of orange flavour were added according to the recipe in order to improve the appearance and taste. The juice was then filled hot into sterilized bottles, corked and allowed to cool in a refrigerator before sampling for analysis and consumption. 


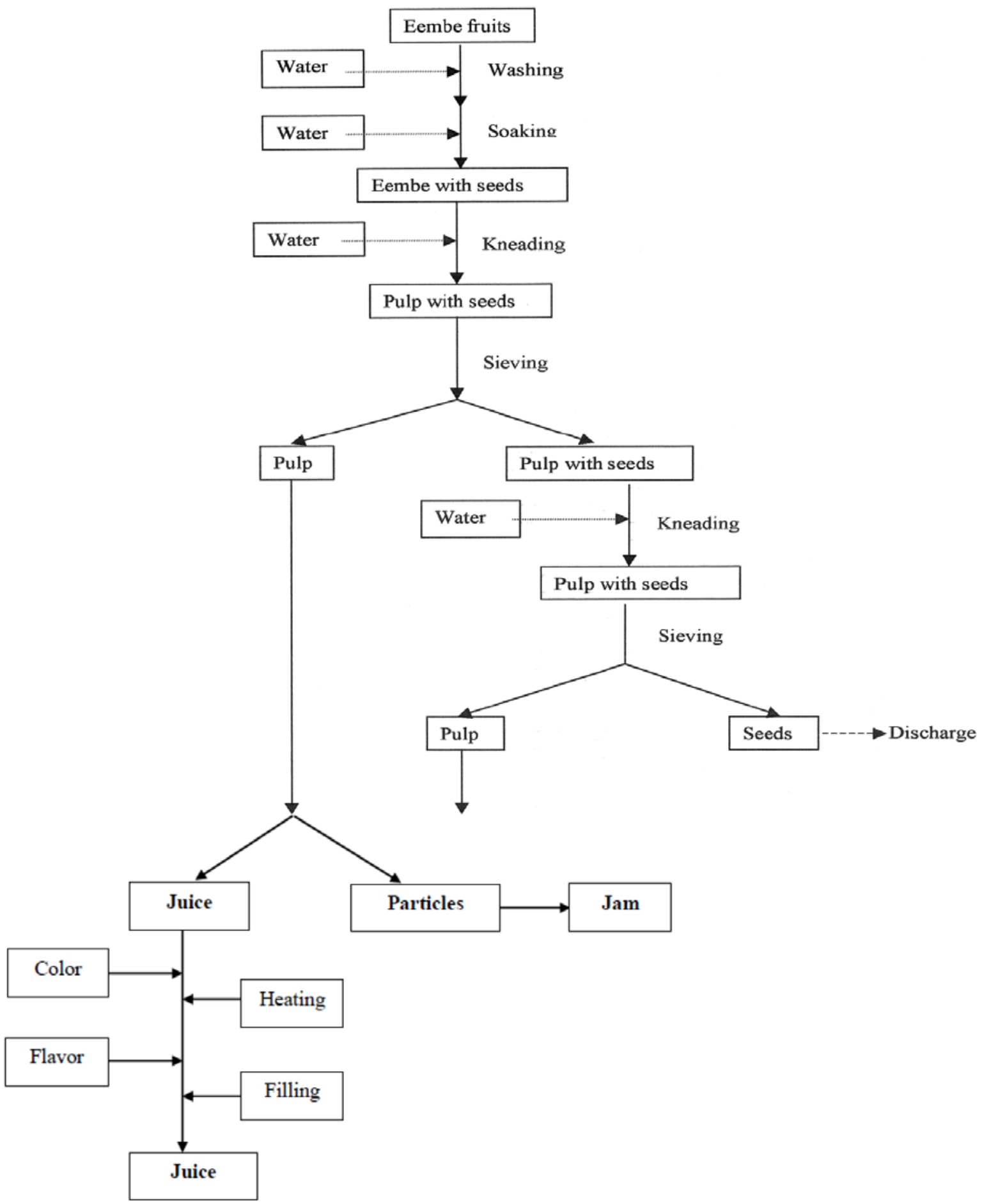

Figure7: Flow chart for processing juice from eembe 


\section{Processing of jam from Eembe}

An amount of $2 \mathrm{~kg}$ of Eembe extract was boiled to cook the pulp. 10 g pectin was mixed with some sugar to prevent lumping as stated previously, and was then dissolved into the pulp (Fig. 8).

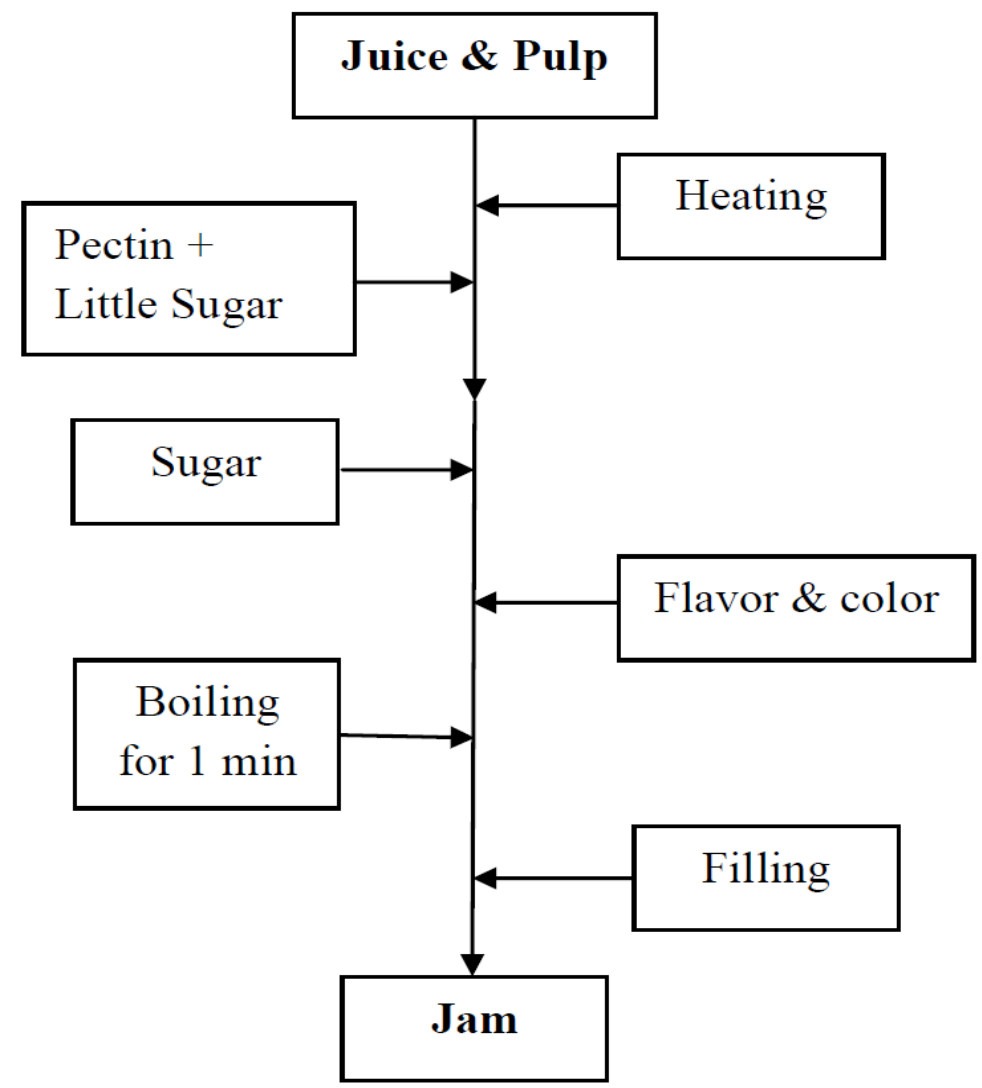

Figure 8: Flow chart for processing jam from eembe

The rest of the sugar $(1 \mathrm{~kg})$ and 1 teaspoon of egg yellow colour and 2 teaspoons of banana flavour were added and mixed. The mixture was again brought to a boil and kept boiling for one minute before filling hot into sterilized jars, sealed, tilted to sterilize head space and allowed to cool overnight at room temperature to jell. Samples were taken at this stage for analysis and use.

\section{Processing of Muffins from Eembe}

The process of making muffins from eembe was similar to the one from Monkey Orange (Fig. 9) but using its own ingredients. 


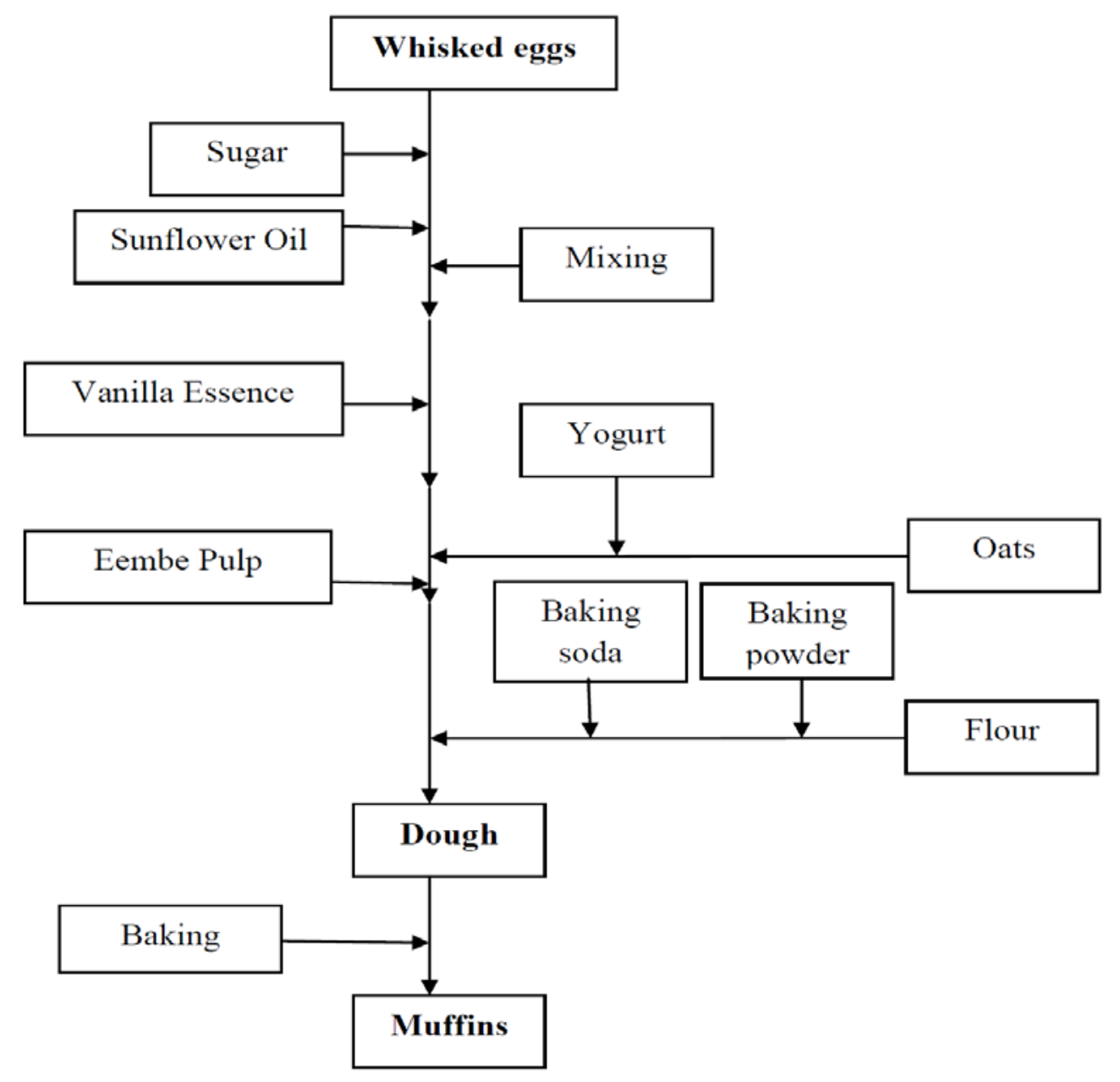

Figure 9: Flow chart for processing muffins from eembe

An amount of $90 \mathrm{~g}$ of Oats were soaked in $150 \mathrm{ml}$ of yoghurt for 10 minutes. While soaking, dry ingredients like $250 \mathrm{~g}$ of cake flour, 1 teaspoon of baking powder and $1 / 2$ teaspoon of baking soda were mixed. An egg was whisked until the colour changed to white. $140 \mathrm{~g}$ sugar, $80 \mathrm{ml}$ sunflower oil, $80 \mathrm{ml}$ of vanilla essence and $150 \mathrm{~g}$ of fresh Eembe pulp were mixed .The oat-yoghurt mixture was then incorporated into all the ingredients and dough was made and pieces were cut and transferred into the greased molds for proofing and baked at $180^{\circ} \mathrm{C}$ for 30 minutes or to a golden brown colour. Muffins were allowed to cool and were ready for sensory evaluation the following day.

\section{Quality control during processing}

All the processes in this study were carried out under Good Manufacturing Practices (GMPs) and Hazard Analysis Critical Control Points (HACCP) systems in order to achieve optimal food quality standard [23]. Personnel, water, environmental hygiene and packaging are of prime importance in this respect. When a new product is developed, the following parameters are usually considered namely; shelf life, safety, 


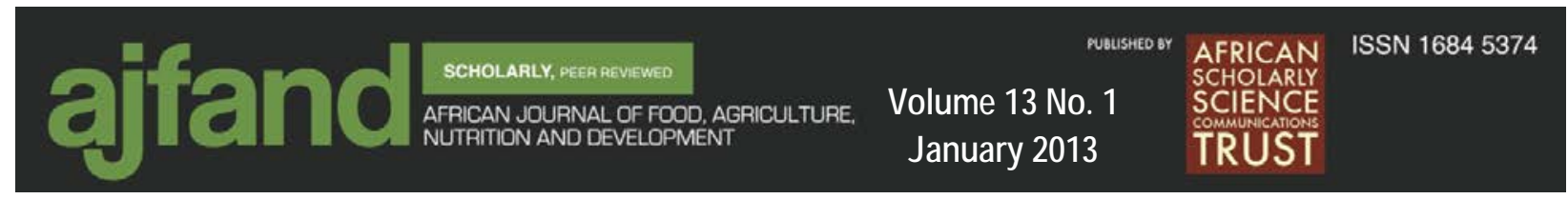

nutrition, flavour, taste, colour and consistency. Microorganisms may infect fruits and cause diseases. Pasteurization temperature of $80^{\circ} \mathrm{C} / 30$ min was used to all the juices except jam and jelly which were boiled in order to cook the pulp, eliminate enzymes (enzymatic deterioration) and to kill microorganisms. High sugar content is also used as a preservative. It is therefore important to establish a sound quality control system so as to safeguard consumer safety, similar to those of exotic products.

\section{Enumeration of total plate counts and Coliform}

Only Total Plate Counts and Coliform (as indicator) Counts were determined in each sample. Ten $\mathrm{ml}$ of each sample was diluted in $90 \mathrm{ml}$ of sterile Ringer's solution and mixed thoroughly. One $\mathrm{ml}$ of each sample was serially diluted using sterile quarterstrenght Ringer's solution and appropriate dilutions were then plated using pour-plate method, as described by Venderzant and Splittstoesser [24]. Total aerobic counts were determined on Eugon's Agar (Oxoid, Hampshire, England) while Coliform counts were carried out on Red Bile Agar (Oxoid, Hampshire, England) incubated at $37 \pm 1^{\circ} \mathrm{C}$ for $48 \mathrm{~h}$. Confirmation of the presence of Coliform was carried out in 2\% Brilliant Green Bile Broth (Oxoid, Hampshire, England) with inverted Durham tubes incubated at $45^{\circ} \mathrm{C}$. Evolution of gas and production of acid were considered as positive results for Coliform.

\section{Consumer sensory evaluation}

Thirty nine participants, women and men who were trained on this value addition project were used as panelists to evaluate the products they made on preference. The trainees were given one week training on how to evaluate the products. The rating test was simplified and limited to consumer preference. Each person was asked to taste three coded samples of each product and score each product for preference on a fivepoint scale, ranging from "most preferred" (preference score =1) to the "least preferred" (preference score $=5$ ). They were provided with samples in labeled Styrofoam cups with plastic spoons for sampling and tasting of the products. This process was repeated three times in three days and the results were recorded for statistical analysis.

\section{Statistical analysis}

All the mean data were statistically analyzed to determine the degree of preference using the one way ANOVA procedure of SPSS version 15. The significance was set at the $5 \%$ level of probability [25].

\section{RESULTS}

In this study; four food items were made from marula, monkey orange and eembe fruits namely; juice, jam, jelly and muffins according to their flow charts (Figures 19). The preference score results are shown in Table 1 . The preference score for marula juice was a bit low (2.3) due to its low $\mathrm{pH}$ of 3.2-3.5 and harsh flavour. Its final $\mathrm{pH}$ was adjusted to $\mathrm{pH} 4.0$ by neutralizing with a food quality $0.1 \mathrm{~N}$ Sodium Hydroxide $(\mathrm{NaOH})$ solution in order to improve on its acceptability. Eembe products had problems with flavour and colour and were all down graded. Eembe juice had a score of 3.20, jam 2.95 and jelly 2.31 despite the addition of food flavour and colour. The 


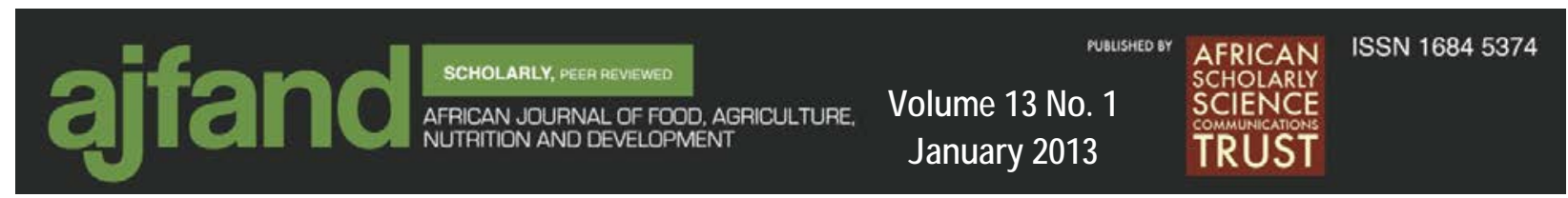

rest of the products were of good quality and were all accepted and preferred by $90 \%$ of the panellists. The products which showed unattractive appearance and taste like those of eembe, food colours and flavours were added to improve their acceptability and preference. Bleaching of natural eembe dark brown colour before the addition artificial food colour could have further improved its appearance and enhance its acceptability, but this was not done and was left for future research work.

The monkey orange pulp was used to produce juice, jam and muffins with stable shelf life. The colour was pure light orange but then it became dark brown during processing. The taste was sweet and delicate. The flavours of these products were distinguished and very pleasant. The taste, smell and appearance of the muffins were good and were well preferred (Table 1). The pulp was refreshing and its taste had been variously described as "a combination of citrus and pineapple" or "a mixture of citrus and banana” [14].

The blue-green fruits of eembe, $20 \times 8 \mathrm{~mm}$ in size that turns greenish yellow to pale orange when ripe was used to make jam, juice and muffins. The size and colour of the fruits were similar to those described by Van Wyk and Gericke [14]. Eembe fruits were just sweet and without distinct flavour. The products were fairly good and tasty after the addition of artificial flavour and colour and they were eventually accepted (Table 1). The results of total plate counts and Coliform counts were all negative. Therefore, all the samples were without bacterial growth. They were not significantly different $(\mathrm{p}<0.05)$ and that they complied with the SA Standard Specifications [26] and were safe for consumption. In sensory evaluation, out of 39 panellists, 35 (90\%) accepted and preferred all the products from the three fruits mentioned earlier. Four panellist (10\%) thought that some of the products were either too acidic and the colour were not attractive enough (Table 2).

\section{DISCUSSIONS}

In the present study; different valued added product were produced from three indigenous fruits in Namibia namely; Marula (Sclerocarya birrea), Monkey orange (Strychnos cocculoides) and Eembe (Berchemia discolour). Although all the products from the three fruits were finally accepted, the acidity of some of the products especially marula juice was a bit harsh and this is attributed to the presence of high contents of vitamin C (ascorbic acid) and citric acid [16,17]. Hilman et al., [15] reported that the marula juice contains 2 to 10 times the amount of ascorbic acid found in orange juice and a higher antioxidant capacity than other species commonly thought to be rich in antioxidant. The taste and colour of the marula jam and jelly were preferred and acceptable (Table 1). Marula has many uses and it is recognized as a commercial, medicinal and cultural important plant species in Namibia and Southern Africa [16,17,27]. Marula has been identified as one of the five fruit tree species that should be integrated in the domestication process in farming systems in Africa to support nutrition, health and income generation of rural communities [16]. Marula pulp has a unique flavour and is used to make juices, nectars, jam and tea or processed into alcoholic beverages such as Amarula [17,27]. From socio-economic point of view; this great and treasured species has the potential to help build a line of 


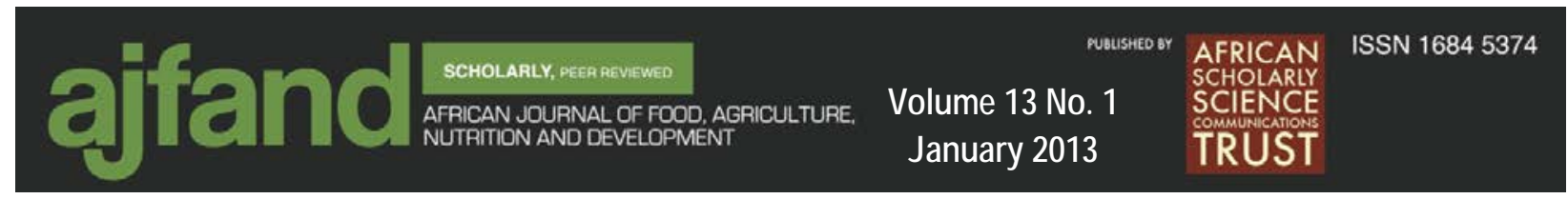

defence against dietary insecurity. Marula provides food during the season when grain stocks have run low and other crops are not ready for harvesting. Throughout the plant's range, and especially where cereal crops are unreliable, villagers pile up marula seeds for food emergencies.

Three value added products were produced in this study (fig. 4-6). The colour change for the monkey orange products during processing is due to the caramelization and maillard reactions. To the best of our knowledge; this seems to be the first study that Strychnous cocculoides is processed into different food products in Namibia and Southern Africa. Production of various food items from monkey orange (Strychnous cocculoides) exploits the high nutrients content of the fruits especially vitamins (C, A, B complex), minerals ( $\mathrm{K}, \mathrm{Ca}, \mathrm{Mg}, \mathrm{P}$ ) and antioxidants [28]. The products would therefore enrich the diet of the rural communities if these products are made readily available. The fruit flavour from marula and monkey orange can be utilized in the dairy and other soft drink industries for making yoghurts, sour milk, ice cream, juices and jams. In socio-economically speaking, monkey orange is important for food security, it has been called "a great and precious resource of food in times of crop failure". The tasty fruits are widely enjoyed and have the amazing capacity to stay edible in tropical heat for months. These are important resources for the future and seemed likely to prove valuable resource for delivering a more secure life to those without access to finances [29].

Eembe fruits in the present study were used to produce juice, jam and cakes but only after the addition of artificial flavour and colour (Fig.7-9). The processing method used in this project produces safer products from eembe fruits with longer shelf life than those based on the traditional way of processing it into rolls or cakes which are just boiled and eaten, as described by Rodin [30]. The production of cakes from eembe is also a refinement of the products described by Venter and Venter, [29]. Also fruits when soaked in water can be pounded, mixed with pearl millet fresh powder to make a soft sweet paste that is eaten after cooking or roasting. However, it was difficult to make juice of acceptable appearance and taste from these fruits (Table 1). It was established that juice from half ripened fruits had an unattractive brownish colour, while the juice made using fully ripened yellow fruits had a more appealing colour. The juice had acceptable taste after the addition of banana essence. Similar tastes were experienced with jam from this fruit. The muffins (cakes) however, had a good taste, color and smell [9].

Regarding to the microbiological quality of the processed products; according to Pilgrim et al. [31] reported that jams and jellies depend on their high sugar concentration for microbiological stability. The inhibition of microorganisms in the processed products (marula juice) in this study could be attributed to the high acidity ( $\mathrm{pH}$ 3.2-3.5). This result is in agreement with Khouryieh et al. [32] and Policarpo et al. [33] of which high acidity is one reason for microorganisms' inhibition. According to the statistical analysis (table 1); Eembe products were downgraded with scores of $3.2 \pm 0.28$ for juice, $2.95 \pm 0.29$ for jam and $2.31 \pm 0.27$ for jelly and they were significantly different $(<0.05)$ from the others. It was only marula juice which had a problem with acidity and was downgraded $(2.30 \pm 0.86)$ despite neutralization. It was 


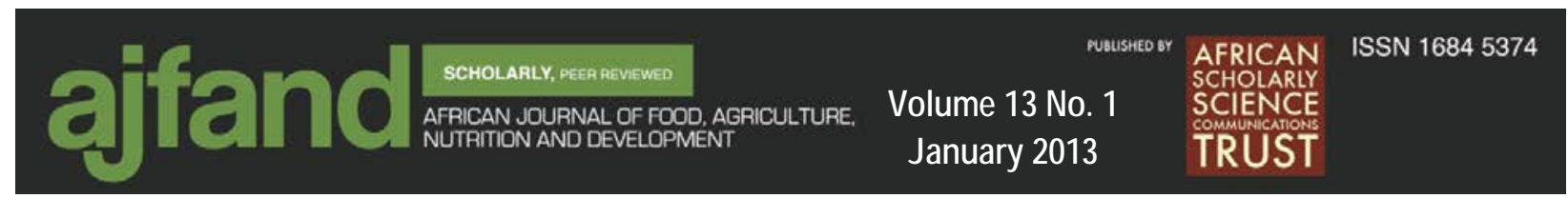

mentioned earlier that some of the products especially from Eembe fruits were not attractive enough as they were dark, so colour had to be added. Bleaching process could further improve the colour. This was left for future research. The Marula products, especially juice on the other hand, was too acidic and had to be neutralized to a $\mathrm{pH}$ of 4.0 to be palatable. In general, the products were acceptable and preferred by $90 \%$ of the consumer panelists (table 2 ).

Africa owns a large number of indigenous fruits which are largely untapped resource that can be used to combat malnutrition and improve the welfare of rural community and development in Africa. Processing of the indigenous fruits concentrates, produces shelf stable and safer products than unprocessed fruits. If these products are made available in large quantities, the nutrition and the standard of living of rural communities could improve. The important contribution that the indigenous fruit trees can make to poverty reduction has been recognized [34]. The domestication of indigenous fruit trees can play an important role in poverty reduction and deserves greater attention in national planning processes. This includes the need for governments to recognize the benefits of indigenous fruit trees to the rural communities in order to protect and create a more favorable market environment. This should include fewer restrictions to transportation and market regulations on these products. This should include the provision of micro-credits for indigenous fruit treebased enterprises [35].

\section{CONCLUSION}

Results of this study showed that good quality commercial products can be made from marula, monkey orange and eembe fruits. The processed fruit products include: juice jams, jellies and muffins. Taste, colour and $\mathrm{pH}$ of the processed products were also evaluated and subjected to sensory evaluation process. The fruit flavour from marula and monkey orange can be utilized in new dairy and soft drink products for making yoghurts and ice-creams. General microbiological quality indicator (Coliforms and Total Plate Counts) to assure the absence of mesophilic, psychrotrophic, total Enterobacteriaceae, total Coliforms, faecal Coliforms and total E. coli counts were performed. The results were all negative and this assured long shelf-life quality and safety of the products for human consumption. Sensory preference tests indicated that $90 \%$ of the panelists preferred the products. The technology and skills acquired from training of rural community on value addition of these fruits is recommended. This will help to reduce poverty by creating jobs and generating income for food security and general welfare of the community in Namibia and elsewhere in Africa. These trees should be domesticated to improve on fruit production and to add value in order to enrich the indigenous fruits on the market.

\section{ACKNOWLEDGEMENTS}

The authors would like to acknowledge the Ministry of Agriculture, Water and Forestry for recruitment to carry out the work, Department of Food Science and Technology of the University of Namibia for providing initial processing and training facilities and FAO for funding the project. We would also like to acknowledge the Multidisciplinary Research Centre (MRC) of the University of Namibia for financial support regarding publication of this research work. 
Table 1: Preference mean scores for value added products of three indigenous fruits

\begin{tabular}{lccc}
\hline Products & Marula & Monkey orange & Eembe \\
\hline Juice & $2.30 \pm 0.86$ & $1.39 \pm 0.77$ & $3.20 \pm 0.28$ \\
Jam & $1.40 \pm 0.77$ & $1.28 \pm 0.52$ & $2.95 \pm 0.29$ \\
Jelly & $1.38 \pm 0.76$ & N/A & $2.31 \pm 0.27$ \\
Muffins & N/A & $1.57 \pm 0.68$ & $1.62 \pm 0.56$ \\
\hline
\end{tabular}

\pm Standard deviation

Table 2: Percentage of consumer preference tests for the products

\begin{tabular}{llll} 
Panellists & Preferred & Disliked* & Percentage \\
\hline
\end{tabular}

\begin{tabular}{llll}
39 & 35 & - & $90 \%$ \\
\hline 39 & - & 4 & $10 \%$ \\
\hline
\end{tabular}

*: Reasons for dislike: Too acidic and dark unattractive colour 


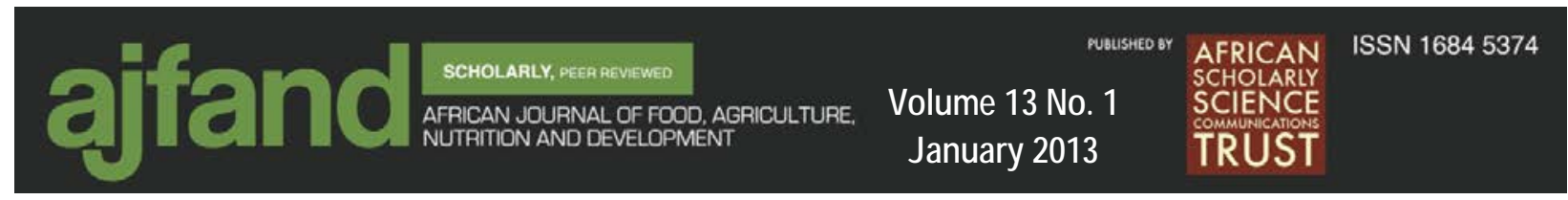

\section{REFERENCES}

1. Leong LP and G Shui An investigation of antioxidant capacity of fruits in Singapore markets. Food Chem. 2002; 76:69-75.

2. Egea IP, Sanchez-Bel FR and MT Pretel. Six edible wild fruits as potential antioxidant additives or nutritional supplements. Plant Foods Hum. Nutr., 2010; 65: 121-129.

3. Isabelle M, Lee BL, Lim BL, Koh BL, Huang D and CN Ong Antioxidant activity and profiles of common fruits in Singapore. Food Chem. 2010; 123: 77-84.

4. World Health Organization and Food and Agricultural Organization Diet, nutrition and the prevention of chronic diseases. In Report of a Joint WHO/FAO Expert Consultation. Geneva: World Health Organization, 2003.

5. Amarteifio JO and MO Mosase The Chemical Composition of Selected Indigenous Fruits of Botswana. J. Appl. Sci. Environ. Mgt. 2006; 10(2): 43 47.

6. Musaba EC and E Sheehama The socio-economic factors influencing harvesting of Eembe (Berchemia discolor) wild fruits by communal households in the Ohangwena region, Namibia. Namibia Dev. J., 2009; 1: 112.

7. Motlhanka DMT, Motlhanka $\mathbf{P}$ and $\mathbf{T}$ Selebatso Edible indigenous wild fruit plants of Eastern Botswana. Int. J. Poult. Sci., 2008; 7: 457-460.

8. Shackleton SE, Shackleton CM, Cunninggham AB, Lombard C, Sullivan CA and TR Netshiluvhi Knowledge on Sclerocarya birrea subsp. Caffra with emphasis on its importance as a non-timber forest product in South and Southern Africa: A summary, Part 1: Taxonomy, ecology and role in rural livelihoods. Southern Afr. Forestry J., 2002; 194: 27-41.

9. Bille PG and G Steppich Transformation of veld fruits into value added products and training. FAO/Directorate of Forestry workshop for rural women in the north and north east of Namibia held at Rundu 17th and 19th November 2003, Rundu, FAO Document, 2003: Pp: 1-31.

10. Cheikhyoussef A, Naomab E, Potgieter S, Kahaka G, Raidron C and HM Ashekele Physiochemical Properties of a Namibian Indigenous plant; Eembe (Berchemia discolor). Proceedings of the 1st National Research Symposium, 15-17 September, Windhoek, Namibia 2010.

11. Sun-Waterhouse D The development of fruit-based functional foods targeting the health and wellness market: A review. Int. J. Food Sci. Tech. 2011; 46(5): 899-920. 
12. Somogyi LP, Ramaswamy HS and YH Hui Processing Fruits: Science and Technology. Vol. 1: Biology, Principles and Applications. Tecnomics Publ. Co. Lancaster, PA, 1996: p824.

13. Omobuwajo $\mathbf{T}$ New technologies and products development and evaluation of lemon-based soft drink. Discovery Innovat., 1998; 10:12-14.

14. Van Wyk BE and N Gericke People's plants: A guide to Useful Plants of Southern Africa. Briza Publications, Republic of South Africa, 2000; pp: 151.

15. Hilman Z, Mizrahi Y and E Beit-Yannai Evaluation of valuable nutrients in selected genotypes of marula (Sclerocarya birrea Subsp. Caffra) Sci. Hortic., 2008; 117:321-328.

16. Leakey RRB Potential for novel food products from agroforestry trees: a review. Food Chem., 1999; 66: 1-14.

17. Fox FW and MEN Yong Food from the veld. Delta books, Johannesburg, South Africa, 1982; Pp: 64, 79-81, 260-261, 312-313.

18. Shackleton S Livelihood benefits from the local level commercialization of savanna resources: A case study of the new and expanded trade in marula (Sclerocarya birrea) beer in Bushbuckridge, South Africa. South Afr. J. Sci. 2004; 100: 651-657.

19. Barrion S, Keya EL and TN Ngwira Country-wine making from Eembe fruit (Berchemia discolor) of Namibia. The Journal of Food Technology in Africa, 2001; 6(3): 83-86.

20. Wehmeyer AS Edible Wild Plants of Southern Africa: Data on Nutrient Contents of over 300 Species. National Food Research Institute, Pretoria, 1986; Pp: 46.

21. Resurreccion A V A Consumer sensory testing for product development. Aspen Publ., Inc., Gaithersburg, Maryland, 1998.

22. Wichchukita S and M O'Mahony Liking', 'Buying', 'Choosing' and 'Take Away' preference tests for varying degrees of hedonic disparity. Food Quality and Preference, 2011; 22: 60-65.

23. FAO. Food Quality and Safety Systems: A Training Manual on Food Hygiene and the Hazard Analysis and Critical Control Point (HACCP) System. FAO, Rome, 1998.

24. Vanderzant $\mathbf{C}$ and DF Splittstoesser Compendium of methods for the microbiological examination of food $3^{\text {rd }}$ Ed. American Public Health Association, 1992: 837-843. 


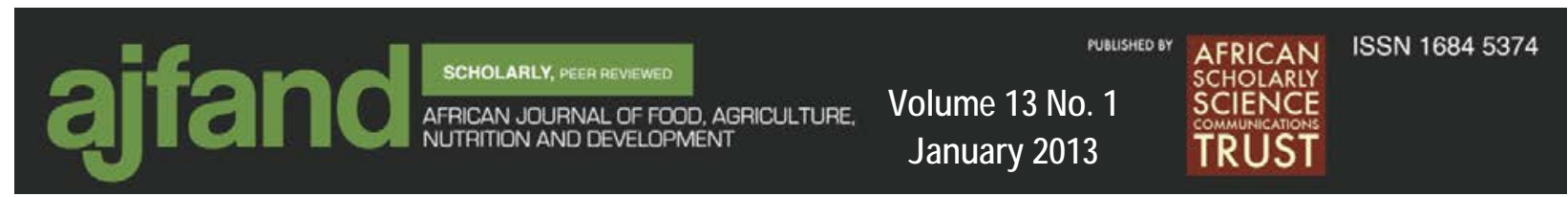

25. Roessler EB, Pangborn RM, Sidel $\mathbf{J L}$ and $\mathbf{H}$ Stone Expanded statistical tables for estimating significance in paired-preference, paired-difference, duotrio and triangle tests. J. Food Sci., 1978; 43: 940-943.

26. SAN ISO/IEC.4832 Microbiology of Food and Animal Feeding Stuff. South Africa Bureau of Standards, 2006.

27. Ojewole JAO, Mawoza T, Chiwororo WDH and PMO Owiro Sclerocarya birrea (A Rich) Hochst, ['Marula'] (Anacardiaceae): a review of its phytochemistry, pharmacology and toxicology and its ethnomedicinal uses. Phytother. Research, 2010; 24: 633-639.

28. Sattar A, Diz M and DL Frankin Competitiveness of food processing cluster in Namibia. Small and Medium Enterprise Competitiveness Enhancement Program (SMECEP). U.S. Agency for International Development, 2003.

29. Venter $\mathbf{F}$ and JA Venter Making the most of indigenous Trees. Briza Publications, Pretoria, Republic of South Africa, 1996.

30. Rodin RJ The Ethnobotany of the Kwanyama Ovambos, Monograph in Systematic Botany. In: Smith N and SA Mori (Eds). Monographs in Systematic Botany from the Missouri Botanical Garden Vol. 9, Missouri Botanical Garden, USA, 1985: p:63.

31. Pilgrim GW, Walter RH and DG Oakenful. Jams, jellies, and preserves. In The Chemistry and Technology of Pectin (R.H. Walter, ed.) pp. 23-50, Academic Press, Inc., San Diego, CA. 1991.

32. Khouryieh, HA, Aramouni, FM and TJ Herald. Physical, chemical and sensory properties of sugar-free jelly. Journal of Food Quality, 2005; 28: 179190.

33. Policarpo VMN, Borges SV, Endo E, DE Castro FT, Anjos VD and NV Cavalcanti. Green umbu (Spondias tuberosa Arr. Cam.) preserve: Physical, chemical and microbiological changes during storage. J. Food Process. Preserv. 2007; 31: 201-210.

34. Schreckenberg K, Awono A, Degrande A, Mbosso C, Ndoye O, and Z Tchoundjeu Domesticating indigenous fruit trees as a contribution to poverty reduction. Forests, Trees and Livelihoods, 2006; 16: 35-51.

35. Akinnifesi FK, Mngomba SA, Sileshi G, Ajayi OC and JL Mhango First and second generation research efforts on commoditizing indigenous fruit tree crops in Southern Africa. Acta. Hortic., 2009; 806: 637-646. 